\title{
Çocuklara Uygulanan Ortodontik Tedavilere İlisskin Youtube Videolarının İçeriklerinin Değerlendirilmesi
}

\author{
Evaluation of The Content of The Youtube ${ }^{\mathrm{TM}}$ Videos on Orthodontic \\ Treatments for Children
}

\author{
Kübra Gülnur TOPSAKAL ${ }^{* * 1}$ (i \\ gulnurbarut@hotmail.com
}

\author{
Merve AKSOY ${ }^{2}$ (D) \\ mervekurun@hotmail.com
}

\author{
Ayşe Selenge AKBULUT ${ }^{3}$ iD \\ selengeakbulut@gmail.com
}

\begin{abstract}
ÖZ
Amaç: Bu çalışmada YouTubeTM video platformunda bulunan ve çocuklarda ortodontik tedavi ile ilgili bilgi veren videoların bilgi içeriklerinin değerlendirilmesi amaçlanmıștır.

Gereç ve Yöntemler: YouTube ${ }^{\mathrm{TM}}$ video platformuna "çocuklarda ortodontik tedavi" terimi girilerek tarama yapıldıktan sonra arama sonucunda çlkan ilk 60 videonun URL'leri kopyalanmıș ve dahil edilme kriterlerine göre toplam 21 video değerlendirilmiştir. Videolara ait izlenme, beğenilme, beğenilmeme ve yorum sayısı, video süresi, videonun yüklendiği tarihten itibaren geçen gün sayısı, etkileşim indeksi, izlenme oranı ve video kaynağı bilgileri kaydedilmiş ve bu videolara yönelik özelliklerin tanımlayıcı istatistikleri minimum, maksimum, ortalama, standart sapma, sıra ortalaması, sıra toplamı ve frekans ve yüzde olarak ifade edilmiştir. Ayrıca içerik analizi için iki gözlemci ortalaması 4 ve üzeri puan alan videolar zengin, 4'ün altı puan alan videolar ise fakir içerikli video olarak sınıflandırılmıștır.

Bulgular: Değerlendirmeye alınan videoların izlenme sayısı ortalaması 4524,14( $\pm 15232,23)$, beğenilme sayısı ortalaması 29,00( $\pm 95,02)$, beğenilmeme sayısı ortalaması 4,95( $\pm 19,77)$, yorum sayısı ortalaması 19,57( $\pm 86,26)$, video uzunluğu ortalaması $5: 25( \pm 4: 53)$, sistemde bulunma gün ortalaması $1178,62( \pm 842,00)$, etkileșim indeksi ortalaması 1,32 $( \pm 2,07)$, izlenme oranı ortalaması $394,61( \pm 1332,13)$ ve içerik analizi ortalaması $3,52( \pm 1,50)$ olarak tespit edilmiştir. İçerik analizi bulgularına göre fakir içerikli videoların \%60'ı hekimler tarafından üretilirken, zengin içerikli videolarda bu oran \%45,5’tir. Ayrıca zengin içerikli video sürelerinin sıra ortalaması $(13,91)$, fakir içerikli video sürelerinin sıra ortalamasından $(7,80)$ istatistiksel anlamlı olarak daha yüksek seviyede bulunmuştur ( $\mathrm{p}=0,024)$.

Sonuç: Çocuklarda ortodontik tedavi ile ilgili YouTube ${ }^{\mathrm{TM}}$ video platformunda yer alan videolar bilgi sağlama yönünden yetersizdir. Hekimler, ebeveynleri doğru bilgileri edinebilmeleri için profesyonel kaynaklara yönlendirmeli ve hekimler bu platformda daha kaliteli içerikler üretmeye özen göstermelidir.
\end{abstract}

Anahtar Kelimeler: Ortodonti, Çocuk Diş Hekimliği, Koruyucu Diş Hekimliği, İnternet
Geliş: 30.10 .2021
Kabul: 14.12 .2021
Yayın: 29.12.2021

\begin{abstract}
Aim: In this study, it is aimed to evaluate the content of the videos on the YouTubeTM video platform that provide information about orthodontic treatment in children.

Material and Methods: After searching the YouTube ${ }^{\mathrm{TM}}$ video platform by entering the term of "orthodontic treatment in children", a total of 21 videos were evaluated according to the exclusion criteria. The number of interaction index, viewing rate and video source were recorded. In addition, videos with an average score of 4 and above that scored by two observers for content analysis were classified as rich, and videos with a score below 4 were classified as poor content.

Results: The average number of views of the evaluated videos is $4524.14( \pm 15232.23)$, likes $29.00( \pm 95.02)$, dislikes 4.95( \pm 19.77$)$, comments $19.57( \pm 86.26)$, video length $5: 25( \pm 4: 53)$, day since upload $1178.62( \pm 842.00)$, interaction index $1.32( \pm 2.07)$, viewing rate $394.61( \pm 1332.13)$ and content analysis mean $3.52( \pm 1.50)$. According to the content analysis findings, $60 \%$ of the videos with poor content are produced by dental professionals, while this rate is $45.5 \%$ for videos with rich content. In addition, mean rank of videos with rich content (13.91) was found to be statistically significantly higher than the mean time of video with poor content $(7.80)(p=0,024)$.

Conclusion: The videos on the YouTube ${ }^{\mathrm{TM}}$ video platform about orthodontic treatment in children are insufficient in terms of providing information. Dental professionals should direct parents to professional resources so that they can obtain correct information, and care should be taken to produce higher quality content on this platform.
\end{abstract}

Keywords: Orthodontics, Pediatric Dentistry, Preventive Dentistry, Internet

$\begin{array}{lll}\text { Received: } 30.10 .2021 & \text { Accepted: } 14.12 .2021 & \text { Published: } 29.12 .2021\end{array}$

Atıf / Citation: Topsakal KG, Aksoy M, Akbulut AS. Çocuklara uygulanan ortodontik tedavilere ilișkin youtube videolarının içeriklerinin değerlendirilmesi. NEU Dent J. 2021;3:108-14.

\footnotetext{
* Sivas Cumhuriyet Üniversitesi 1. Uluslararası Diș Hekimliği Kongresi’nden sözlü sunum olarak sunulmuștur.

** Sorumlu Yazar / Corresponding Author

1. Sağlık Bilimleri Üniversitesi Gülhane Diş Hekimliği Fakültesi Ortodonti AD, Ankara, Türkiye

2. Sağlık Bilimleri Üniversitesi Gülhane Diş Hekimliği Fakültesi Çocuk Diş Hekimliği AD, Ankara, Türkiye

3. Karamanoğlu Mehmetbey Üniversitesi Diş Hekimliği Fakültesi Ortodonti AD, Karaman, Türkiye
} 


\section{Gíriş}

Dünya Sağlık Örgütü'ne göre ortodontik malokluzyon; fonksiyonu engelleyerek estetik malformasyona neden olan, hastayı fiziksel ve duygusal olarak etkileyen, bu nedenle de ortodontik bir müdahale gerektiren dișsel ve/veya iskeletsel anomalidir. Çocuklarda süt ve karma dișlenme dönemindeki erken teșhis sayesinde malokluzyonlar saptanabilmekte ve doğru müdahale ile bu malokluzyonların daimi dentisyona aktarılması önlenmektedir. ${ }^{1}$ Bu durum erken diş hekimi kontrolünün ve dolayısıyla bilinçli ebeveynliğin önemini göstermektedir. Günümüzde ebeveynler bu tarz durumları fark ettiklerinde bilgi almak amaciyla çeşitli kaynaklara başvurabilmektedirler, bunlardan bazıları da sosyal medya platformlarıdır.

Günümüzde sosyal medya ve sosyal ağlar hayatımızda önemli bir yere sahiptir. Bunun sonucu olarak da sosyal medya kullanımının yıllara göre dağılımına baktığımız zaman sürekli artan bir eğri çizdiği görülmektedir. ${ }^{2}$ Bu sosyal ağlardan birisi olan ve 2005 yılında açılan Youtube ${ }^{\mathrm{TM}}$ 'da sağlıkla ilgili bilgileri yaymak için her geçen gün daha fazla kullanılan bir platform olmuştur. ${ }^{3}$ Günümüzde ikinci en fazla ziyaret edilen site olan Youtube'un, ücretsiz video paylaşımı sunması, her video için beğenme, beğenmeme ve yorum yapma özelliklerinin bulunması ve yayınlanan videoların içeriğinin çeșitliliği sosyal etkisinin rolünü açıklamaya katkıda bulunur. ${ }^{4}$ YouTube, bireylerin kendi sağlık problemleri ilgili bilgilerini araștırmak ve sahip oldukları bilgileri yaymak için kullandıkları ve her geçen gün daha fazla kişiye ulaşılan bir platform olmuştur. ${ }^{3}$ Health Information National Trends Survey (HINTS) sağlık bilgilerine erişim için internet kullanımında son zamanlarda artış olduğunu bildirmektedir. Anketler, 10 internet kullanıcısının 8'inin sağllk bilgilerine çevrimiçi olarak eriştiğini ortaya çıkarmıștır. ${ }^{5,6} \mathrm{Bu}$ sonuçlar, YouTube platformunun, video deposu bir sosyal ağ olarak kişilerin sağlıkla ilgili bilgilere ulaşmak, kendi bilgilerini paylașmak ve yaymak için önemli bir araç olma potansiyeline sahip olduğunu göstermektedir. Ayrıca ebeveynlerin ağız diş sağlığı alanındaki farkındalığının çocukların dental tedavi ihtiyaçlarını belirlediği de bilinmektedir. ${ }^{3} \mathrm{Bu}$ etkileşimi doğru yönetip, sağlık hizmetleri üzerinde faydalarını teşhis yardımı amacıyla kullanmak veya sağlık hizmeti koşulları için bir eğitim aracı olarak görmek değerlendirilmesi gereken bir durumdur.

Literatürde çeşitli sağlık konularında YouTube videolarının kalitesini ve içeriğini analiz eden çeșitli araștırmalar bulunmaktadır ${ }^{7-9}$ fakat çocuklarda ortodontik tedavilerle ilgili bilgi veren videoları inceleyen herhangi bir çalışmaya rastlanmamıştır. $\mathrm{Bu}$ çalışmanın amacı çocuklarda ortodontik tedavilerle ile ilgili Türkçe olarak yüklenen YouTube ${ }^{\mathrm{TM}}$ videolarının sağladığı bilgilerin içeriğini değerlendirmek, bu videoların hastalar için etkinliğini ortaya koymaktır.

\section{GEREÇ VE YÖNTEMLER}

Çalışmamız, insanlarda ya da insanlardan alınan örneklerde yapılmadığı ve kamuya açık bir internet sitesi kullanılarak gerçekleștirildiği için etik kurul onayına ihtiyaç duyulmamıştır. Çalışmada ebeveynlerin kullanabileceği arama terimi olarak 'Çocuklar ve Ortodontik Tedavi' başlığının kullanılması tercih edilmiștir. Yapılan çalıșmalarda Youtube'u kullanan izleyicilerinden \%90 kadarı arama sonuçlarından ilk üç sayfaya baktığı tespit edilmiştir. Bu sayfalarda aradıklarını bulamayan izleyicilerden $\% 79$ 'unun ise diğer sayfalara baktığı görülmüştür. ${ }^{10}$ Bu nedenle çalışmamızda da ilk 61 video değerlendirmeye alınmış ve arama sonuçları farklı günlerde değişebileceğinden kaynak bulucular (URL'ler) yedeklenmiştir (25 Ağustos 2021). 61 video dahil edilme kriterlerine göre, iki araştırmacı tarafından değerlendirilmiştir. Daha sonra araştırmacılar arasındaki güvenilirlik indeksi hesaplanmıștır.

Dahil edilmeme kriterlerine göre videoların \%65,5'i $(\mathrm{n}=40)$ araştırma kapsamına alınmamıștır. Videoların \%1,6'sı (n=1) sesli anlatım olmaması, \%3,2'si $(\mathrm{n}=2)$ reklam olması, \%13,1'i (n=8) çok uzun olması, $\% 22,9$ 'i $(n=14)$ yorumlara kapalı olması ve $\% 24,5^{\prime} \mathrm{i}$ $(n=15)$ ilgisiz konu içermesi nedenleri ile araștırma kapsamında çıkarılmıştır. Bu bulgulara göre videoları \%34,5'i (n=21) araștırma kapsamında değerlendirmeye alınmıştır (Şekil 1).

Ayrıca videoların her biri için așağıdaki parametreler kaydedilmiș ve sırasıyla etkileșim indeksi (\%) ve İzlenme Oranı (\%) hesaplanmıştır: ${ }^{10}$

\section{Başlık ve URL bilgisi \\ 2. Video uzunluğu (dakika olarak) \\ 3. Yüklenme tarihi}

4. Yüklenme tarihinden bugüne kadar geçen zaman (gün olarak)

5. Yüklemeyi kimin gerçekleştirdiği (Klinik, diş heki$\mathrm{mi}$, ticari)

6. Görüntülenme sayısı,

7. Beğeni ve beğenmeme sayısı,

8.Yorum sayısı

Etkileșim İndeksi (\%) = ((Beğeni Sayısı-Beğenmeme SayısI)/(Görüntülenme Sayısı) $) \times 100$

İzlenme Oranı (\%) = ((Görüntülenme Sayısı) $/($ Yüklemenin Üzerinden Geçen Zaman))×100

Youtube videolarını değerlendirirken kullanılan içerik analizinde belirlenen başlıklar: Ortodontik tedavinin tanımı (1), ortodontik tedavinin zamanı ve yaşı (2), ortodontik tedavinin endikasyonları (3), ortodontik tedavinin kontrendikasyonları (4), hekim ziyareti gerekliliği (5), ortodontik tedavi prosedürü 
(6), ortodontik tedavinin maliyeti (7) ve ortodontik tedavinin avantajı (8) olarak seçilmiştir. İki gözlemci tarafından 8 farklı kategoride değerlendirilen YouTube videoları ilgili konu bașlığına değinilip değinilmemesine göre 0 ya da 1 puan verilecek șekilde değerlendirilmiş olup, iki gözlemcinin ortalaması 4 ve üzeri puan olan videolar zengin, 4'ün altı puan olan videolar ise fakir içerikli video olarak sınıflandırılmıştır.

\section{İstatistiksel Analiz}

Araştırma kapsamında incelenen YouTube videolarına yönelik özelliklerin tanımlayıcı istatistikleri minimum, maksimum, ortalama, standart sapma, sıra ortalaması, sıra toplamı ve frekans ve yüzde olarak ifade edilmiştir. Araştırma gruplarında normal dağılım varsayımının değerlendirilmesi amacıyla Shapiro-Wilk testi kullanılmıștır. Gruplardaki verilerin normal dağılım sergilememeleri sebebi ile ikili grup karşılaștırmalarında Mann Whitney U testi kullanılmiștır.

İçerik değerlerinin gözlemciler arası tutarlılığının değerlendirilmesi amaciyla ise Cohen's Kappa testi kullanılmıștır. İçerik değerlerinin gözlemci ölçüm ortalamaları $(\mathrm{n}=2)$ analizlerde kullanılmıștır. Verilerin istatistiksel analiz sürecinde SPSS 26 istatistik yazılımından faydalanılmıştır. $\mathrm{p}<0,05$ istatistiksel olarak anlamlı kabul edilmiștir.

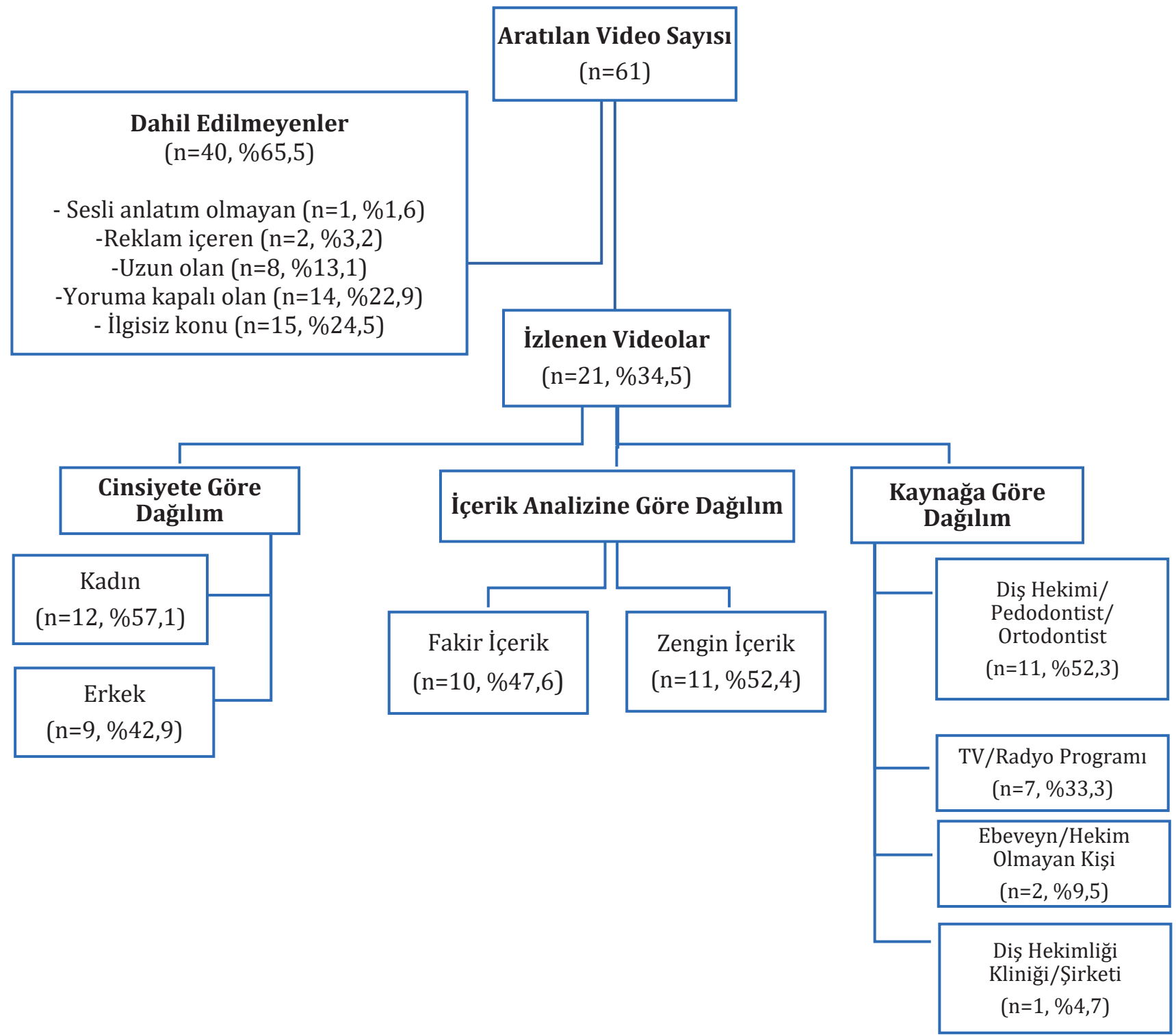




\section{BULGULAR}

Tablo 1'de içerik değerlerinin gözlemciler arası tutarlılığının değerlendirmesi amacıyla uygulanan analiz bulguları görülmektedir.

Tablo 1'de görüldüğü üzere iki gözlemcinin içerik analizi değer ölçmeleri arasında istatistiksel anlamlı olarak yeterli seviyede uyum görülmektedir (Kappa Value $=0,847, \mathrm{p}<0,001$ )
Değerlendirmeye alınan videoların izlenme sayısı ortalaması $4524,14( \pm 15232,23)$, beğeni sayısı ortalaması $29,00( \pm 95,02)$, beğenilmeme sayısı ortalaması $4,95( \pm 19,77)$, yorum sayısı ortalaması 19,57 $( \pm 86,26)$, video uzunluğu (dk.) ortalaması 5:25 $( \pm 4: 53)$, videonun yüklenmesinin üzerinden geçen zaman ortalaması $1178,62( \pm 842,00)$, etkileșim İndeksi ortalaması $1,32( \pm 2,07)$, izlenme oranı ortalaması 394,61 $( \pm 1332,13)$ ve içerik analiz puanı ortalaması 3,52 $( \pm 1,50)$ olarak tespit edilmiştir.

Tablo 1: İçerik değerinin gözlemciler arası tutarlılığının değerlendirilmesi

\begin{tabular}{|c|c|c|c|c|c|c|c|c|c|}
\hline & & & \multicolumn{6}{|c|}{$\begin{array}{c}\text { İÇERİK ANALİZİ } \\
\text { (İkinci Araştırmacı) }\end{array}$} & \multirow[t]{2}{*}{ Toplam } \\
\hline & & & 1 & 2 & 3 & 4 & 5 & 6 & \\
\hline \multirow{12}{*}{$\begin{array}{c}\text { İÇERİK ANALİŻ } \\
\text { (Birinci Araştırmacı) }\end{array}$} & \multirow{2}{*}{1} & $\mathrm{n}$ & 3 & 0 & 0 & 0 & 0 & 0 & 3 \\
\hline & & $\%$ & 100,0 & 0,0 & 0,0 & 0,0 & 0,0 & 0,0 & 100,0 \\
\hline & \multirow{2}{*}{2} & $\mathrm{n}$ & 0 & 1 & 1 & 0 & 0 & 0 & 2 \\
\hline & & $\%$ & 0,0 & 50,0 & 50,0 & 0,0 & 0,0 & 0,0 & 100,0 \\
\hline & \multirow{2}{*}{3} & $\mathrm{n}$ & 0 & 0 & 4 & 0 & 0 & 0 & 4 \\
\hline & & $\%$ & 0,0 & 0,0 & 100,0 & 0,0 & 0,0 & 0,0 & 100,0 \\
\hline & \multirow{2}{*}{4} & $\mathrm{n}$ & 0 & 1 & 0 & 5 & 1 & 0 & 7 \\
\hline & & $\%$ & 0,0 & 14,3 & 0,0 & 71,4 & 14,3 & 0,0 & 100,0 \\
\hline & \multirow{2}{*}{5} & $\mathrm{n}$ & 0 & 0 & 0 & 0 & 3 & 0 & 3 \\
\hline & & $\%$ & 0,0 & 0,0 & 0,0 & 0,0 & 100,0 & 0,0 & 100,0 \\
\hline & \multirow{2}{*}{6} & $\mathrm{n}$ & 0 & 0 & 0 & 0 & 0 & 2 & 2 \\
\hline & & $\%$ & 0,0 & 0,0 & 0,0 & 0,0 & 0,0 & 100,0 & 100,0 \\
\hline \multirow{2}{*}{ Toplam \% } & & $\mathrm{n}$ & 3 & 2 & 5 & 5 & 4 & 2 & 21 \\
\hline & & 14,3 & 9,5 & 23,8 & 23,8 & 19,0 & 9,5 & 9,5 & 100,0 \\
\hline
\end{tabular}

Kappa Değeri: 0,824, p<0,001, (CI: 0,639-1,00)

Tablo 2: İncelenen videoların tanımlayıcı bulguları

\begin{tabular}{|c|c|c|c|c|}
\hline Tanımlayıcı Bulgular & Minimum & Maximum & Ortalama & SS. \\
\hline Görüntülenme Sayısı & 60,00 & 70447,00 & 4524,14 & 15232,23 \\
\hline Beğeni Sayısı & 0,00 & 440,00 & 29,00 & 95,02 \\
\hline Beğenmeme Sayısı & 0,00 & 91,00 & 4,95 & 19,77 \\
\hline Yorum Sayısı & 0,00 & 396,00 & 19,57 & 86,26 \\
\hline Video Uzunluğu (dk.) & $00: 37$ & $14: 04$ & $5: 25$ & $4: 53$ \\
\hline $\begin{array}{c}\text { Yüklenme Üzerinden } \\
\text { Geçen Zaman }\end{array}$ & 101,00 & 2806,00 & 1178,62 & 842,00 \\
\hline Etkileşim İndeksi & 0,00 & 7,58 & 1,32 & 2,07 \\
\hline İzlenme Oranı & 4,95 & 6179,56 & 394,61 & 1332,13 \\
\hline İçerik Analizi Puanı & 1,00 & 6,00 & 3,52 & 1,50 \\
\hline
\end{tabular}

SS: Standard Sapma 
Tablo 3'te araştırma kapsamında değerlendirilen videoların demografik özelliklerinin içerik kategorilerine göre dağılımları görülmektedir.

Tablo 3'te görüldüğü üzere, fakir içerikli videoların \%60' $1(n=6)$ diş hekimleri, pedodontist, veya ortodontistler, \%10'u $(n=1)$ hekim harici kiși, \%10'u $(\mathrm{n}=1)$ dental klinik veya șirketler, \%20'si $(\mathrm{n}=2) \mathrm{TV}$ programı tarafından üretilmiștir. Zengin içerikli videoların ise \%45,5'i (n=5) diş hekimleri, pedodontist veya ortodontistler, \%9,1'i ( $\mathrm{n}=1)$ hekim harici kişi, $\% 45,5$ 'i (n=5) TV programı tarafından üretilmiștir. Ayrıca fakir içerikli videoların \%60’ı (n=6) kadınlar tarafından, \%40'ı (n=4) erkekler tarafından üretilirken, zengin içerikli videoların ise \%54,5'i (n=6) ka- dınlar, \%45,5’i (n=5) erkekler tarafından üretilmiştir.

Tablo 4'te araştırma kapsamında incelenen video özelliklerinin içerik kategorileri açısından değerlendirilmesi amacıyla uygulanan analiz bulguları görülmektedir.

Tablo 4'de görüldüğü üzere zengin içerikli video sürelerinin sıra ortalaması $(13,91)$, fakir içerikli video sürelerinin sıra ortalamasından $(7,80)$ istatistiksel anlamlı olarak daha yüksek seviyede bulunmuştur $(p=0,024)$. Ancak araștırma kapsamında incelenen videoların diğer özellikleri içerik kategorileri açısından istatistiksel olarak anlamlı farklılık göstermemektedir $(p>0,05)$.

Tablo 3: İncelenen videoların içerik kategorileri açısından dağılımı

\begin{tabular}{|c|c|c|c|}
\hline & $\begin{array}{c}\text { Fakir İçerik } \\
(n=10) \text { N (\%) }\end{array}$ & $\begin{array}{l}\text { Zengin İçerik } \\
(n=11) \text { N }(\%)\end{array}$ & $\begin{array}{l}\text { Toplam } \\
\text { N (\%) }\end{array}$ \\
\hline \multicolumn{4}{|l|}{ VİDEONUN KAYNAĞI } \\
\hline Diş Hekimi, Pedodontist, Ortodontist & $6(60,0)$ & $5(45,5)$ & $11(52,4)$ \\
\hline Hekim Harici Kişi & $1(10,0)$ & $0(0,0)$ & $1(4,8)$ \\
\hline Diş Hekimliği Kliniği/Şirketi & $1(10,0)$ & $1(9,0)$ & $2(9,5)$ \\
\hline TV Programı & $2(20,0)$ & $5(45,5)$ & $7(33,3)$ \\
\hline \multicolumn{4}{|l|}{ KAYNAĞIN CİNSIYYETİ } \\
\hline Erkek & $4(40)$ & $6(54,5)$ & $10(47,6)$ \\
\hline Kadın & $6(60)$ & $5(45,5)$ & $11(52,4)$ \\
\hline Toplam & $10(100,0)$ & $11(100,0)$ & $21(100,0)$ \\
\hline
\end{tabular}

Tablo 4: Araştırma kapsamındaki değişkenlerin içerik kategorileri açısından değerlendirilmesi

\begin{tabular}{|c|c|c|c|c|c|}
\hline & \multicolumn{2}{|c|}{$\begin{array}{l}\text { Fakir İçerik } \\
\quad(n=10)\end{array}$} & \multicolumn{2}{|c|}{$\begin{array}{l}\text { Zengin İçerik } \\
\quad(n=11)\end{array}$} & \multirow{2}{*}{ p değeri* } \\
\hline & $\begin{array}{c}\text { Sira } \\
\text { Ortalaması }\end{array}$ & Sira Toplamı & $\begin{array}{c}\text { Sira } \\
\text { Ortalaması }\end{array}$ & Sira Toplamı & \\
\hline Görüntülenme Sayısı & 10,30 & 103,00 & 11,64 & 128,00 & 0,654 \\
\hline Beğeni Sayısı & 10,40 & 104,00 & 11,55 & 127,00 & 0,705 \\
\hline Beğenmeme Sayısı & 10,15 & 101,50 & 11,77 & 129,50 & 0,557 \\
\hline Yorum Sayısı & 9,65 & 96,50 & 12,23 & 134,50 & 0,349 \\
\hline Video Uzunluğu (dk.) & 7,80 & 78,00 & 13,91 & 153,00 & 0,024 \\
\hline $\begin{array}{c}\text { Yüklenme Üzerinden } \\
\text { Geçen Zaman }\end{array}$ & 11,40 & 114,00 & 10,64 & 117,00 & 0,809 \\
\hline Etkileşim İndeksi & 10,35 & 103,50 & 11,59 & 127,50 & 0,644 \\
\hline İzlenme Oranı & 9,70 & 97,00 & 12,18 & 134,00 & 0,387 \\
\hline
\end{tabular}




\section{TARTIŞMA}

Bu çalışmada, çocuklarda ortodontik tedavi ile ilgili Youtube videoları incelenmiştir. Literatürde Youtube'daki videoların tıp ve diş hekimliği alanındaki bilgi düzeylerini araştıran çalışmalar mevcuttur. ${ }^{7-12}$ Ancak yapılan literatür taramasında çocuklarda ortodontik tedavi ile ilgili videoların incelendiği bir çalışmaya rastlanmamıștır. Biz de bu çalışmada sağlık hizmeti veren kișilerin Youtube'da yer alan videolardaki bilgilerin farkında olup hastalarını doğru şekilde yönlendirmesini ve sağlık hizmeti alan kişilerin de doğru kaynaklardan yararlanmasını sağlamak amacıyla bu videoları değerlendirmek istedik.

Yapılan çalışmalarda Youtube'un hastalıkların teșhisinde, tedavisinde ve önlenmesinde en çok başvurulan sosyal medya platformlarından biri olduğu görülmüștür. ${ }^{13}$ Fakat Youtube'da bulunan videoların kalitesi ve bilgi düzeyi ile ilgili hala soru işaretleri bulunmaktadır. Youtube kolay ulaşılabilirliği ve içerik çeşitliliği nedeniyle de güçlü bir kaynaktır ancak çoğu içeriğin kaynağı bilimsel verilerden ziyade kişisel deneyimlere dayanmaktadır. Youtube'da diş hekimliği ile ilgili geniş bir video perspektifinin olduğu ve ortodontik tedavi gören çocuk hastaların ve ebeveynlerinin bu datalardan yararlandığı görülmektedir. ${ }^{14}$ Bunun yanında Youtube'da bulunan videoların içerdiği bilgilerin doğruluğu hala sorgulanabilirdir. ${ }^{15}$

Çalışmamızdan elde ettiğimiz veriler, Youtube kullanıcılarının çocuklarda ortodontik tedavi ile ilgili videoları sıklıkla yüklediklerini, izleyicilerin bu videoları izleme, beğeni ve yorum yapma özelliği sayesinde diğer kullanıcılarla sık sık iletişim halinde olduğunu göstermiștir. Çalışmamızda 4 ve üzeri puan alan videolar zengin 4'ün altı puan alan videolar ise fakir içerikli video olarak sınıflandırılmıştır. Buna bağlı olarak çalışmamızda analizimize göre izlenen bütün videoların içerik analiz puanı ortalamanın altındadır. Bu da Youtube'un çocuklarda ortodontik tedavi hakkında bilgi kaynağı olarak yetersiz olduğunu göstermektedir. Araștırmamızda incelenen konu başlıklarının hepsinden bahseden bir video olmamasının ve yüklenen videoların çoğunun, belirtilen konulardan birini ya da birkaçını içermesinin düşük içerikli videoların sayısında artışa neden olduğu düşünülmektedir. Üstdal ve ark. yaptıkları çalışmada da bizim sonuçlarımız ile benzer sonuçlar bulmuşlardır. ${ }^{11}$ Fakat Yavuz ve ark. hızlandırılmış ortodonti ile ilgili YouTube videolarını izledikleri çalışmalarında videoların içeriğin mükemmel olduğunu, öte yandan videoların hala tam olarak güvenilir olmadığını bildirmişlerdir. ${ }^{16}$ Lena ve Dindaroglu da yaptıkları çalışmalarında araştırdıkları konular hakkında Youtube'un yeterli video kalitesine sahip olmadığını bulmuşlardır. ${ }^{10}$
Yüklenen videoların kaynakları incelendiğinde, bu içeriklerin çoğunlukla diş hekimi, pedodontist, ortodontist ve TV programları tarafından olușturulduğu bulunmuștur. Yavuz ve ark. ${ }^{16}$ da yaptıkları çalışmada videoların çoğunlukla akademik kurumlar, ortodontistler ve diş hekimleri tarafından yüklendiğini belirtmiştir. Bu çalışmanın sonuçları da bizim sonuçlarımızı desteklemektedir. Ayrıca çalışmamızın bulgularına göre istatistiksel olarak anlamlı olmamakla birlikte, zengin içerikli video sayısı fakir içerikli video sayısından daha fazladır. Bu da hekimlerin daha fazla zengin içerik ürettiği sonucumuzu desteklemektedir.

Çalışmamızda zengin içerikli videoların ortalama uzunluğu fakir içerikli videolara göre istatistiksel olarak anlamlı derecede yüksek bulunmuştur. Lena ve Dindaroğlu ${ }^{10}$ da Lingual Ortodonti ile ilgili videoların içeriklerini inceledikleri çalışmalarında zengin içerikli videoların daha uzun süreye sahip olduklarını bulmuşlardır. Bu durum, zengin içerikli videoların daha fazla konu bașlığından bahsetmesi nedeniyle daha uzun video süresine sahip olması ile açıklanabilir.

Youtube dinamik bir ortamdır ${ }^{16}$ ve arama sonuçlarının sırası izleyicilerin neden olduğu etkileșimle ve geçen zamanla da değișmektedir. ${ }^{11}$ Benzer çalışmalarda olduğu gibi veri toplama yönteminin anlık olması çalışmanın kısıtlılıklarındandır. ${ }^{10}$ Ayrıca bu çalışmada Youtube uygulamasındaki sınırlı sayıdaki Türkçe videolar izlenmiștir, yapılacak başka bir çalışmada diğer dillerdeki videolar da izlenerek çalışma geliştirilebilir.

\section{SONUÇ}

Çalıșmamızın sonuçlarına göre, çocuklarda ortodontik tedavi ile ilgili YouTube ${ }^{\mathrm{TM}}$ video platformunda yer alan videolar, bilgi sağlama yönünden yetersizdir. Hekimler, ebeveynleri doğru bilgileri edinebilmeleri için profesyonel kaynaklara yönlendirmeli ve hekimler bu platformda daha kaliteli içerikler üretmeye özen gösterilmelidir.

\section{KAYNAKLAR}

1. Petersen PE. World Health Organization global policy for improvement of oral health-World Health Assembly 2007. Int. Dent. J. 2008;58:115-21.

2. Goel A, Gupta L. Social Media in the Times of COVID-19. J Clin Rheumatol. 2020;26:220-223.

3. Madathil KC, Rivera-Rodriguez AJ, Greenstein JS, Gramopadhye AK. Healthcare information on YoutubeTM: A systematic review. Health Informatics J. 2015;21:173-94.

4. Susarla A, Oh JH, Tan Y. Social networks and the diffusion of user-generated content: Evidence from youtube. Inf Syst Res. 2012;23:23-41. 
5. Atkinson NL, Saperstein SL, Pleis J. Using the internet for health-related activities: Findings from a national probability sample. J Med Internet Res. 2009;11:e5.

6. Rutten LJF, Squiers L, Hesse B. Cancer-related information seeking: Hints from the 2003 Health Information National Trends Survey (HINTS). J Health Commun. 2006;s11:47-56.

7. Abukaraky A, Hamdan AA, Ameera MN, Nasief M, Hassona Y. Quality of YouTube TM videos on dental implants. Med Oral Patol Oral Cir Bucal. 2018;23:e463.

8. Meade MJ, Sooriakumaran P, Dreyer CW. (2020). Orthodontic retention and retainers: Quality of information provided by dental professionals on YouTube. Am J Orthod Dentofacial Orthop. 2020;158:229-236.

9. Işık G, Özden YM. Are YouTube Videos in Turkish Useful as an Information Source for Dental Treatment During the COVID-19 Pandemic?. Internet J Allied Health Sci Pract. 2021;19:18.

10. Lena Y, Dindaroglu F. Lingual orthodontic treatment: A YouTube video analysis. Angle Orthod. 2018;88:20814.
11. Ustdal G, Guney AU. YouTube as a source of information about orthodontic clear aligners. Angle Orthod. 2020;90:419-24.

12. Hatipoğlu Ş, Gaş S. Is Information for Surgically Assisted Rapid Palatal Expansion Available on YouTube Reliable? J Oral Maxillofac Surg. 2020;78:1017.e11017.e10.

13. Singh AG, Singh S, Singh PP. YouTube for information on rheumatoid arthritis-a wakeup call? J Rheumatol. 2012;39:899-903.

14. Knösel M, Jung K. Informational value and bias of videos related to orthodontics screened on a video-sharing Web site. Angle Orthod 2011;81:532-9.

15. Kılınç DD, Sayar, G. Assessment of reliability of YouTube videos on orthodontics. Turk J Orthod. 2019;32:145.

16. Yavuz MC, Buyuk SK, Genc E. Does YouTube offer high quality information? Evaluation of accelerated orthodontics videos. Ir J Med Sci. 2020;189:505-9. 